\title{
CFD Analysis of Modified Rushton Turbine Impeller
}

\author{
I. Jenish $^{\# 1}$, M. Appadurai ${ }^{* 2}$, E. Fantin Irudaya Raj ${ }^{\# 3}$ \\ \#1 Assistant Professor, Department of Mechanical Engineering, \\ Rohini College of Engineering and Technology, Kanyakumari, India \\ ${ }^{2}$ Assistant Professor, Department of Mechanical Engineering, \\ ${ }^{3}$ Assistant Professor, Department of Electrical and Electronics Engineering, \\ ${ }^{2 \& 3}$ Dr. Sivanthi Aditanar College of Engineering, Tiruchendur, India.
}

\begin{abstract}
Mixing units is one of the prime components in various chemical processing industries. The mixing equipment produces a product by combing different liquids at various properties. Generally, the mixing units are axial and radial flow types. The rushton turbine is one of the radial flow types and had higher power number due to fluid resistance as disadvantage. This works aims to investigate the four bladed rushton turbine impellers at eight angles for finding optimum power without compromising radial flow patterns. The shaft eccentricity hydrodynamics effect is also analysed on the unbaffled stirred vessels. The variance of eccentric and coaxial agitation is clearly evaluated on the several power number and impeller blade angle by experimental and numerical analysis. The CFD analysis is made on the mixing chamber to find the optimum inputs of the mixing chamber numerically by varying the blade angles.
\end{abstract}

Keywords - Radial flow type impeller, mixing of fluids, CFD, Rushton turbine.

\section{INTRODUCTION}

Stirred vessels are mostly used to blend the different viscosity fluids, solid-solid mixing, etc., for wide process in pharmaceutical, chemical, pharmaceutical, metallurgical process and food industries. These processes also utilized to treat industrial wastewater as well as municipal and wastewater treatment [1]. From the literature, the co-axial impellers gave optimum effectiveness for mixing low viscosity fluids and the proximity impellers provided best results for blending high viscosity fluids. The comprehensive analyses of the co-axial mixers used in industries have been analysed by Tanguy [2-3]. The vessel diameter, location of impellers, impeller design, diameter, and bottom design, internal factors such as baffles, coils, and draft tube are the parameters which defined the real flow in the mixing chambers [4-7]. The classification of the impellers mainly on the direction of the fluid flow and they classified as radial and axial flow. The rushton turbine is one the radial flow type. The drawback of the rushton turbine is larger power number due to its higher fluid resistance. Finite element analysis gave better results to simulate the mechanical problems for reducing monetary experimental evaluations [8-12].

The current research is aimed to evaluate the outcome of the shaft eccentricity of unbaffled mixing stirred mixers hydrodynamics experimentally and numerical analysis. The main variance between the coaxial and eccentric agitation is properly evaluated by varying different power number and flow pattern of the mixing tank.

\section{MIXING}

The degree of non-uniformity or different system gradients such as concentration, temperature and viscosity is reduced by proper mixing. The current study is aimed to analysis radial flow which is represented in figure 1 . In mixing the materials is moved from one place to another place in the mixing chamber.

\section{RADIAL FLOW IMPELLERS}

The radial flow impellers are mainly utilized for low and medium viscosity fluids mixing. The mixing might be liquid-liquid, gas-liquid dispersion is effectively done by any one of single and multi-phase mixing chambers. Unlike axial flow turbine impellers, the radial flow impellers produced higher turbulence and shear levels on lower mixing speed. The radial flow mixing impellers discharge the fluid radically outward direction towards the vessel wall. By proper designing of baffles, the flows are strongly converted toward top to bottom direction 
and above or below the impellers. This is a true fact that impellers are placed in the tank with the required bottom clearances for better mixing. Generally radial flow type impellers either contain a disk or open flat blade type and also either curved or flat blade type. Radial flow impeller without disc does not produce mixing in a proper radial direction since pressure gradient occurs on either side of the rotating impellers. Radial impellers with disk have higher power consumption and gave uniform radial flow patterns.

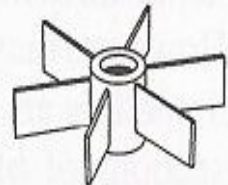

Open Flat Blade

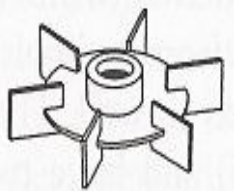

Disk Style (Rushton)

Fig. 1 Radial flow impellers

\section{MODIFIED RUSHTON TURBINE}

The existing model of the rushton turbine is shown in figure. 1. The modified view of the rushton turbine is shown in below (figure.2). It has the blade angle of 10 degree upwards like that changing blade attack angle $20^{\circ}$, $30^{\circ}$ and $45^{\circ}$, upwards and downwards with the same hub diameter. The hub and blades are connected by using nut and bolt assembly.

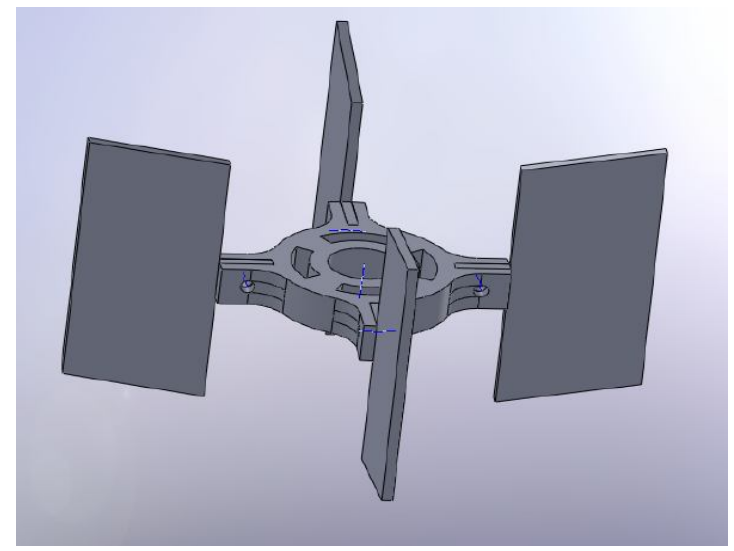

Fig. 2 Modified rushton turbine

The 2-D view of the hub and blade is shown in figure. 3, which denotes the attack angle of the impeller blade is $10^{\circ}$ upwards direction.
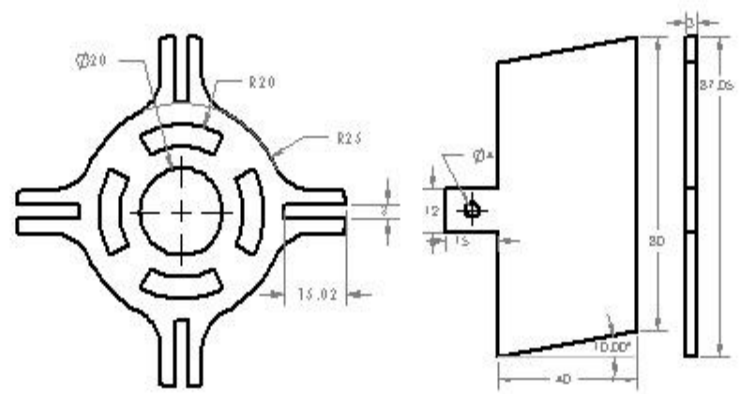

Fig. 3 2-D Model of hub and blade 


\section{GEOMETRY}

The cylindrical stirred tank is used for simulation with flat bottom as shown in figure. 3 . The cylindrical tank has diameter $(\mathrm{T})$ of $0.5 \mathrm{~m}$ and height of $\mathrm{H}=\mathrm{T}$. the rushton turbine has four-bladed turbine impeller with an equivalent diameter of $\mathrm{D}=\mathrm{T} / 3$ was inserted in the tank. The impeller blade width (l) is $\mathrm{D} / 4$ and the impeller blade height $\mathrm{w}$ is equal to $\mathrm{D} / 2$. The off-bottom clearance is $\mathrm{C}=\mathrm{T} / 3$. The working fluid is water. The rotational speed of the impeller was $120 \mathrm{rpm}$. This corresponds to a Reynolds $\mathrm{Re}=\mathrm{ND}^{2} / \mathrm{v}$ of $3.072 \times 10^{3}$. The eccentricity (e) of the impeller is $\mathrm{T} / 4$.

The computational grid is shown in the figure 4. The numbers of nodes in the rushton turbine model are 86341. The solution is solved using $\mathrm{k}-\varepsilon$ model. The discretisation study is made to find the optimum number of nodes and elements for numerical analysis.

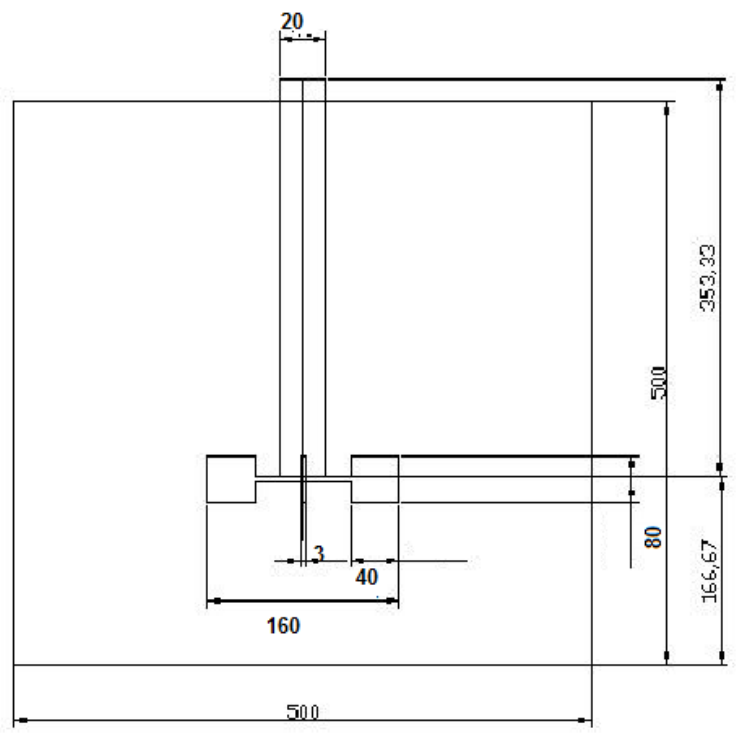

Fig. 4 Typical mixing vessel with an impeller and a shaft

\section{POWER CONSUMPTION RATE}

The CFD model is created to find the optimum parameters of overall power input of the stirred mixing tank. The shear stress and the pressure distribution results are solved in the CFD solver. The CFD results are calculated at varying several parameters of input. The power requirement of the mixing chamber is directly calculated from the total torque of the rotating shaft. The blade torque can be evaluated as

$$
T=\frac{\pi \pi D^{3}}{16}
$$

where, $\mathrm{D}$ is a impeller diameter and $\boldsymbol{\tau}$ is a impeller shear stress.

At a steady state constant rotation, the power requirement for rotation of the impellers is given by,

$\mathrm{P}=2 \pi \mathrm{NT}$

The power number $\left(\mathrm{P}_{0}\right)$ is then computed as:

$P_{0}=\frac{p}{\rho N^{2} D^{5}}$

where, $\mathrm{P}$ is motor power and $\rho$ is density of the fluid.

\section{FLOW NUMBER}

The computational momentum centre coincided with inter section of the shaft $\mathrm{z}$-axis with the impeller at horizontal plane. The impeller radial flow number was evaluated by integrating the axial impeller flow over a circular surface above impeller.

$\mathrm{FL}=\mathrm{Q} / \mathrm{ND}^{3}$ 
where, $Q=\int_{\Pi} R^{2} V_{Z}$ and $V_{Z}$ is an axial velocity of impeller.

\section{RESULTS AND DISCUSSION}

The impeller performance was identified by calculating axial velocity and impeller shear stress by CFD software. The impeller has various attack angles, which were $10^{\circ}, 20^{\circ}, 30^{\circ}$ and $45^{\circ}$ respectively, were four up and four down. Power number and flow number were calculated for all angle of attack from impeller shear stress and axial velocity, which were calculated for power consumption and flow behaviour for all angles. The power number (Figure 5) and flow number (Figure 6) value every angle of attack was compared with existing model (Rushton Turbine impeller). The power number and flow number were calculated by using above formula 2 and 3. The values of power and flow number are given in the below tables. The main factor of affecting power number is power consumed by the motor. It will be changed according to impeller position (Axial or Eccentric) and impeller blade angle. The impeller power number is minimized by reducing impeller blade resistance.

TABLE I VALUES OF POWER NUMBER

\begin{tabular}{|c|c|c|}
\hline IMPELLER MODEL & AXIAL & ECCENTRIC \\
\hline RTI & 0.0077 & 0.25 \\
\hline RTI UP & & \\
\hline RTI-10 & & 0.181 \\
\hline RTI-20 $^{\circ}$ & 0.0076 & 0.18 \\
\hline RTI-30 $^{\circ}$ & 0.0078 & 0.29 \\
\hline RTI-45 $^{\circ}$ & 0.0416 & 0.328 \\
\hline RTI DOWN & 0.052 & \\
\hline RTI-10 $^{\circ}$ & 0.0075 & 0.183 \\
\hline RTI-20 $^{\circ}$ & 0.00786 & 0.181 \\
\hline RTI-30 $^{\circ}$ & 0.0416 & 0.24 \\
\hline RTI-45 $^{\circ}$ & 0.04 & 0.233 \\
\hline
\end{tabular}

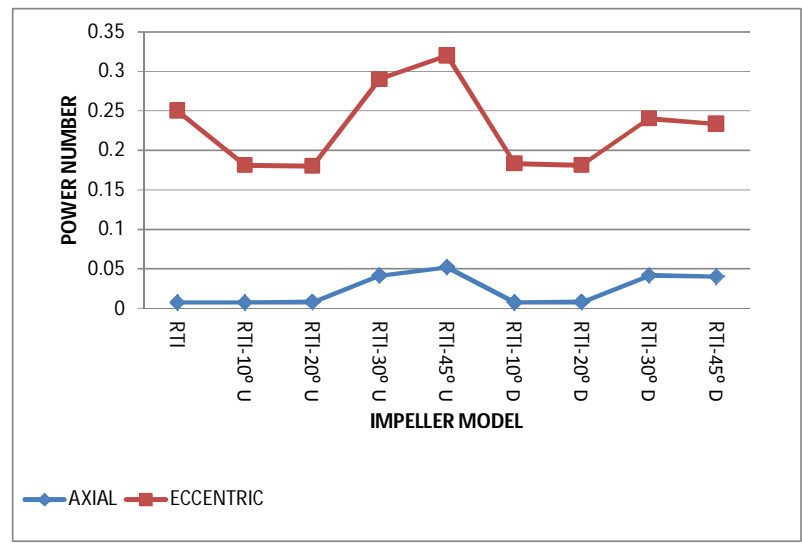

Fig. 5 Impeller model v/s Power number 


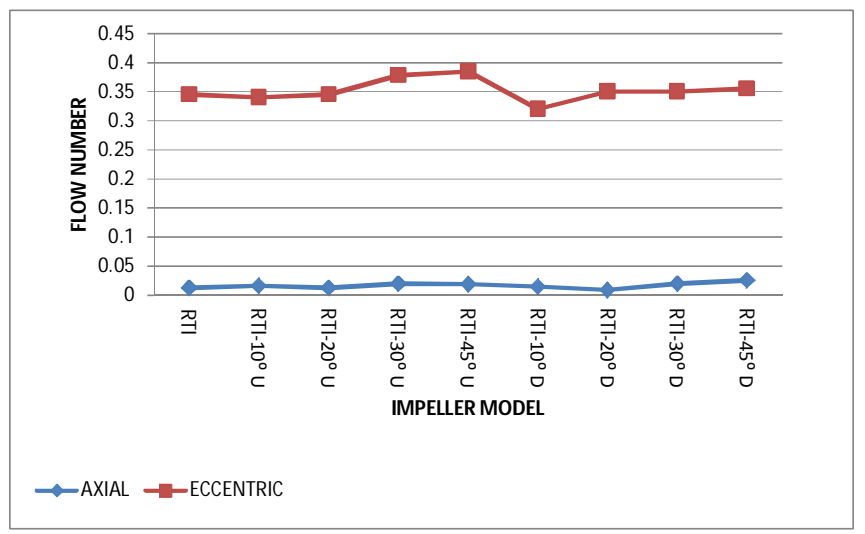

Fig. 6 Impeller model v/s Flow number

TABLE II VALUES OF FLOW NUMBER

\begin{tabular}{|c|c|c|}
\hline IMPELLER MODEL & AXIAL & ECCENTRIC \\
\hline RTI & 0.0125 & 0.345 \\
\hline RTI UP & & \\
\hline RTI-10 & & 0.34 \\
\hline RTI-20 $^{\circ}$ & 0.016 & 0.345 \\
\hline RTI-30 $^{\circ}$ & 0.0127 & 0.378 \\
\hline RTI-45 & 0.02 & 0.385 \\
\hline RTI DOWN & 0.019 & \\
\hline RTI-10 $^{\circ}$ & & 0.32 \\
\hline RTI-20 & 0.015 & 0.35 \\
\hline RTI-30 $^{\circ}$ & 0.009 & 0.35 \\
\hline RTI-45 $^{\circ}$ & 0.02 & 0.355 \\
\hline
\end{tabular}

Basically rushton turbine impeller has high power number because of high fluid resistance. The charts have been drawn between impeller model v/s power number and impeller model v/s flow number is given below.

\section{IX.CONCLUSIONS}

The flow and power number for various angles of attack has been investigated, and charts were drawn. From the results, the power number is $30 \%$ high at RTI $-45^{\circ}$ upward eccentric position, at the mean time the flow number found is $11 \%$ high. The power number is low at RTI $-10^{\circ} \& 20^{\circ}$ in upward eccentric position and the flow number is same compared with rushton turbine impeller.

\section{REFERENCES}

[1] Kumaresan, T. and Joshi, J.B., "Effect of impeller design on the flow pattern and mixing in stirred tanks", Chemical engineering journal, vol. 115(3), pp.173-193, 2006. 
[2] Foucault, S., Ascanio, G. and Tanguy, P.A., "Power characteristics in coaxial mixing: Newtonian and non-Newtonian fluids", Industrial \& engineering chemistry research, vol. 44(14), pp.5036-5043, 2005.

[3] Farhat, M., Fradette, L. and Tanguy, P.A., "Revisiting the performance of a coaxial mixer", Industrial \& engineering chemistry research, vol. 47(10), pp.3562-3567, 2008.

[4] Montante, G., Bakker, A., Paglianti, A. and Magelli, F., "Effect of the shaft eccentricity on the hydrodynamics of unbaffled stirred tanks", Chemical engineering science, vol. 61(9), pp.2807-2814, 2006.

[5] Corkidi, G., Hernández-Cruz, G., Ramos, E. and Ascanio, G., "Visualization of pseudocaverns in stirred vessels", Journal of Engineering Science and Technology, vol. 4(4), pp.344-350, 2009.

[6] Stoots, C.M. and Calabrese, R.V., "Mean velocity field relative to a Rushton turbine blade", AIChE Journal, vol. 41(1), pp.1-11, 1995.

[7] Derksen, J.J., Doelman, M.S. and Van den Akker, H.E.A., "Three-dimensional LDA measurements in the impeller region of a turbulently stirred tank", Experiments in Fluids, vol. 27(6), pp.522-532, 1999.

[8] Appadurai, M., Raj, Fantin Irudaya Raj, E. and Venkadeshwaran, K., "Finite element design and thermal analysis of an induction motor used for a hydraulic pumping system". Materials Today: Proceedings, 2021.

[9] Appadurai, M. and Fantin Irudaya Raj, E, "Finite Element Analysis of Composite Wind Turbine Blades". In 2021 7th International Conference on Electrical Energy Systems (ICEES) (pp. 585-589). IEEE, February 2021.

[10] Raj, E. F. I., \& Appadurai, M. Minimization of Torque Ripple and Incremental of Power Factor in Switched Reluctance Motor Drive. Recent Trends in Communication and Intelligent Systems: Proceedings of ICRTCIS 2020, 125., 2020.

[11] Raj, E. F. I., \& Balaji, M., Analysis and classification of faults in switched reluctance motors using deep learning neural networks. Arabian Journal for Science and Engineering, 46(2), 1313-1332., 2021.

[12] Raj, E. F. I., Available Transfer Capability (ATC) under Deregulated Environment. Journal of Power Electronics \& Power Systems, 6(2), 85-88., 2016 